\title{
AQUISIÇÃO DE ORAÇÕES RELATIVAS NO PB EM CONTEXTO DE INPUT VARIÁVEL
}

Ana Cristina Baptista de Abreu (UFRJ)

Christina Abreu Gomes (UFRJ)

Resumo: Este trabalho focaliza a aquisição de orações relativas por crianças adquirindo o Português Brasileiro em contexto de input variável, considerando os pressupostos da Sociolinguística Variacionista e dos Modelos Baseados no Uso. As relativas infantis iniciais apresentam estruturas mais simples até que as crianças produzam relativas alvo observadas na fala dos adultos. Além disso, o processo desenvolvimental é influenciado pela frequência de ocorrência na fala dessas orações e pelo grau de similaridade estrutural com padrões mais recorrentes da língua. Isto é, as relativas mais frequentes e com a estrutura mais comum na língua são adquiridas primeiro pelas crianças (DIESSEL \& TOMASELLO, 2000, 2005; AMBRIDGE, KIDD, ROWLAND, THEAKSTON, 2015). Considerando que o PB se caracteriza por um processo de mudança das orações relativas (TARALLO, 1986, 1993), nossa hipótese é que a aquisição de relativas também vai refletir a dinamicidade da mudança. A análise de dados de produção espontânea de 23 crianças moradoras da cidade do Rio de Janeiro, componentes da Amostra AQUIVAR/PEUL/UFRJ, mostrou que as relativas infantis refletem a mesma direcionalidade de mudança atestada na fala dos adultos da mesma comunidade de fala, embora contenham características inerentes à fase aquisitiva, (MOLLICA, 2003; ABREU, 2013). Portanto, estes resultados evidenciam que a aquisição depende não só da frequência das estruturas no input, mas também da similaridade que determinadas estruturas apresentam com outras sentenças da língua. Além disso, também fornecem evidência adicional de que as crianças participam da implementação da mudança linguística pelo processo de incrementação (LABOV, 2007; 2010).

Palavras chave: Aquisição; Variação; Mudança; Orações Relativas; Modelos baseados no Uso.

Abstract: This study focus on the acquisition of relative clauses by children acquiring Brazilian Portuguese within variable input, regarding the assumptions of Variationist Sociolinguistics and Usage-based 
Models. Early children relative clauses present simple structures until the children produce target relatives as those observed in adult speech, as well as the developmental process is influenced by the token frequency of these clauses in natural speech and to the degree of structural similarity with more frequent patterns in the language. In other words, more frequent relative clauses with common structures in the language are acquired first by children (DIESSEL \& TOMASELLO, 2000, 2005; AMBRIDGE et al., 2015). Considering that BP is characterized by a process of change in relative clauses (TARALLO, 1986; 1993), we claim that the acquisition of relative clauses by Brazilian Portuguese speakers will reflect the dynamicity of change. The analysis of the data from natural production of 23 children, living in the city of Rio de Janeiro and included in AQUIVAR/PEUL/UFRJ Sample, showed that, although children relatives contain characteristics inherent to the acquisition phase, they reflect the same directionality of change attested in the speech of the adults of the same speech community (MOLLICA, 2003; ABREU, 2013). Therefore, these results show that the acquisition depends on the frequency of the structures in the input and on the similarity that certain structures present with other sentences of the language. Furthermore, they provide additional evidence that children participate in the implementation of the linguistic change through the process of incrementation. (LABOV, 2007, 2010).

Keywords: Acquisition; Variation; Change; Relative Clauses; Usagebased Models.

\section{INTRODUÇÃO}

O uso variável de orações relativas no Português Brasileiro (doravante PB) tem sido amplamente investigado por diversos estudos. Dentre eles destacam-se os trabalhos de Tarallo (1986, 1993) e Mollica (2003). No entanto, há poucos estudos sobre aquisição de relativas por crianças falantes do PB (CORRÊA,1995; PERRONI, 2001; LESSA DE OLIVEIRA, 2008), mas nenhum deles abordou a aquisição considerando a variabilidade 
dessas estruturas e o processo de mudança de acordo com a ótica da Sociolinguística Variacionista, destacando-se apenas o trabalho de Abreu (2013). Além disso, estudos desenvolvidos com base nos pressupostos teóricos dos Modelos baseados no Uso, como Arnon (2011), Diessel \& Tomasello (2000, 2005), Diessel (2009), Diessel \& Hilpert (2016), têm mostrado que, nos processos aquisitivos dessas orações, frequência de ocorrência e frequência de tipo são fundamentais para a emergência dessas estruturas, juntamente com a experiência advinda da interação com os indivíduos.

A pesquisa conjuga tanto os pressupostos teóricos dos Modelos baseados no Uso quanto os pressupostos da Sociolinguística Variacionista, segundo a qual as diferentes formas de orações relativas produzidas pelos falantes do Português Brasileiro são interpretadas como uma variável linguística, uma vez que são consideradas equivalentes semanticamente, isto é, maneiras diferentes de se dizer a mesma coisa com o mesmo significado referencial. Serão apresentadas evidências de que, além dos aspectos desenvolvimentais presentes na aquisição dessas estruturas no PB e em outras línguas, as crianças tendem a refletir o input a que estão expostas também em função dos padrões de distribuição dessas formas na língua. E, no caso do PB, o input se caracteriza em função do estágio de mudança dessas 
estruturas, detectado em trabalhos desenvolvidos no âmbito da Sociolinguística Variacionista (MOLLICA, 1977, 2003; TARALLO, 1986; 1997). A observação da aquisição linguística, neste contexto, pode trazer evidências sobre o papel das crianças no processo de propagação da mudança linguística em uma comunidade de fala em função da implementação da mudança a partir da sequência ininterrupta de transmissão linguística (mudança no sistema - 'change from bellow') através de gerações sucessivas de crianças (aquisição natural) e do processo de incrementação (LABOV, 2007, 2010). Segundo Labov (2007), o processo de incrementação começa com a transmissão fiel do sistema do adulto, que inclui elementos variáveis e seus condicionamentos linguísticos e sociais, além das estruturas categóricas. As gerações sucessivas de crianças avançam a mudança linguística além do nível observado para as gerações anteriores (pais e outros componentes da comunidade de fala com quem interagem) na mesma direção por mais de uma geração. Assim, no processo de aquisição, as crianças alinham as variantes do input com o vetor de idade, de maneira que, quanto mais jovem o falante, mais avançada é a mudança. Em outras palavras, a mudança se propaga gradualmente pela comunidade de fala à medida que determinada variante vai sofrendo diminuição de uso, ao mesmo tempo em que 
outra variante aumenta de frequência de realização, com reflexos na organização do sistema que está sendo adquirido pela criança.

Portanto, o presente artigo apresenta a análise de dados de produção espontânea de 23 crianças com idades entre 1 ano e 9 meses (1;9) e 5 anos (5;0), componentes da Amostra AQUIVAR/PEUL/UFRJ, moradoras da cidade do Rio de Janeiro, com o objetivo de mostrar não só os aspectos desenvolvimentais presentes na aquisição dessas estruturas, como também identificar de que maneira as produções das crianças refletem aspectos presentes no input relacionados com o estágio de mudança do PB, assim como o efeito de padrões de distribuição das variantes observadas no uso adulto. As seções a seguir apresentam a caracterização do PB do ponto de vista da variação na realização de orações relativas, aspectos presentes na aquisição de orações relativas sob a ótica dos Modelos baseados no uso, metodologia e hipóteses de trabalho, resultados e, finalmente, as conclusões.

\section{ORAÇÕES RELATIVAS NO PORTUGUÊS BRASILEIRO}

Esta seção apresenta a caracterização do PB no que diz respeito à abordagem das orações relativas como uma variável sociolinguística a partir dos estudos de Tarallo $(1986,1993)$ e, especificamente da comunidade de fala do Rio de Janeiro, de acordo com os estudos de Mollica (2003) e Abreu (2013). 
Os estudos de Tarallo (1986, 1993) apresentaram evidências de que as orações relativas do PB se apresentam como uma variável linguística e que, especificamente, as orações relativas com funções preposicionadas passam por um processo de mudança. A partir de um corpus composto por peças teatrais, cartas e diários, escritos entre os séculos XVIII e XIX, e de um corpus de fala espontânea, gravado em 1981, foram estabelecidas as seguintes variantes: i) para as relativas em local de extração não preposicionado: a) relativa padrão (doravante denominada básica como em Abreu (2013) e b) relativa copiadora, como nos exemplos em (1) a seguir, respectivamente; e ii) para as relativas em posições preposicionadas: c) relativa padrão, d) relativa copiadora e e) relativa cortadora, como nos exemplos a seguir em (2).

(1) Funções não preposicionadas

a) Relativa Básica: A menina que comprou a bolsa foi para casa.

b) Relativa Copiadora: A menina que ela comprou a bolsa foi para casa.

(2) Funções preposicionadas

c) Relativa Padrão: A roupa de que falei é bonita.

d) Relativa Copiadora: A roupa que falei dela é bonita.

e) Relativa Cortadora: A roupa que falei é bonita.

A partir destes exemplos, é possível perceber que as estruturas a) e b) concorrem entre si nos locais de extração não preposicionados de sujeito e objeto direto. A relativa básica (ou padrão nos termos de Tarallo) é a forma prescrita 
pela gramática escolar. As relativas copiadoras apresentam um pronome anafórico preenchendo a posição de sujeito ou de objeto direto. Para Tarallo (1993), apesar desta concorrência, a relativa copiadora em b) é menos frequente do que a relativa básica (padrão).

Ainda segundo o autor, no caso das posições preposicionadas, a relativa padrão em c) é formada por movimento da preposição e do termo relativizado, enquanto as demais relativas preposicionadas são formadas por apagamento do sintagma correferencial, no caso das copiadoras, e do sintagma correferencial e da preposição, no caso das cortadoras. A relativa copiadora em d) apresenta um sintagma correferente in situ substituindo o referente apagado, fazendo com que a lacuna seja preenchida por uma cópia, mantendo a preposição. Já na relativa cortadora, há a supressão do sintagma correferente que inclui a preposição, como no exemplo e), deixando uma lacuna na posição preposicionada. Além disso, as relativas padrão, copiadora e cortadora também não têm o mesmo espaço de ocorrência. Segundo Tarallo (1986, 1993), houve uma mudança nas estratégias de relativização no $\mathrm{PB}$, de maneira que as relativas padrão começaram a desaparecer em posições preposicionadas e passaram a ser substituídas por relativas cortadoras. 
Tarallo (1993) explica esta mudança nas estratégias de relativização como decorrente de uma mudança na retenção pronominal, evidenciando o reflexo do encaixamento das mudanças linguísticas, conforme afirmam Weinreich, Labov \& Herzog (1968). Para Tarallo, a baixa retenção pronominal começou a atingir as posições preposicionadas por volta de 1880 , por este motivo começou a haver maiores taxas de apagamento dos sintagmas correferenciais, fazendo com que aumentassem as taxas das relativas cortadoras. Desta forma, as relativas copiadoras e cortadoras já predominavam em comparação às relativas padrão em 1880, período em que a mudança no sistema de retenção pronominal propiciou uma nova organização do sistema, provocando a tendência ao desaparecimento da relativa padrão com função preposicionada e o crescimento da relativa cortadora decorrente do apagamento do sintagma referencial e da preposição.

As relativas na fala carioca foram investigadas por Mollica (2003), a partir de dados de fala de adultos moradores da cidade do Rio de Janeiro, para observar o padrão de uso da comunidade de fala no que concerne à relativização. Com este objetivo, Mollica (2003) observou os falantes que compunham duas amostras de fala espontânea: uma gravada em 1980, denominada Amostra Censo 80 (C), e outra com 
gravações feitas em 1999 e 2000, denominadas Amostra Censo 00 (I), com 16 informantes da Amostra Censo 1980, e Amostra Censo 00 (C), composta por outros 48 falantes da referida comunidade de fala. Além de Mollica, Abreu (2013) também realizou um levantamento na fala dos adultos participantes da amostra 00 (C), a fim de coletar as relativas produzidas que caracterizam o input para a aquisição.

Mollica (2003) investiga se há uma mudança no uso das relativas, se os "parâmetros controladores são semelhantes nas décadas de 1980 e 1990" (p.130), e se fatores sociais predominam sobre os fatores estruturais. Investiga também quais as diferenças de comportamento entre os mesmos indivíduos e a comunidade em dois momentos e se é possível explicar o encaixamento das relativas frente a outras estruturas sintáticas do Português. Os resultados obtidos mostraram que as relativas mais comuns na fala carioca são as variantes cortadoras das funções preposicionadas. Além disso, observa que o uso da cópia foi de $6 \%$ nos 16 indivíduos recontados nas Amostras 80 (I) e 00 (I), resultado que também se repetiu nas Amostras 80 (C) e 00 (C). Desta forma, os comportamentos dos indivíduos e da comunidade de fala se mostraram estáveis, no que diz respeito à variante copiadora. 
A observação do comportamento do indivíduo e da comunidade de fala, respectivamente nos estudos de painel ${ }^{1}$ e tendência ${ }^{2}$, evidenciou o efeito da escolaridade, idade e sexo na variação. Foram controladas também a animacidade do referente, a função sintática deste e a distância entre o SN referente e o termo que introduz a oração. Desta forma, os resultados obtidos revelaram que a cópia é mais frequente quando há um elemento entre o referente e o pronome relativo, contexto em que o elemento relativizador se encontra distante de seu referente. Além disso, Mollica (2003) afirma que, nestes casos, a cópia também tem a função de eliminar a ambiguidade que pode ser causada pela distância entre relativizador e referente. ${ }^{3}$ Também foi observado que a presença de referentes animados aumenta a chance de ocorrer uma cópia. Já em relação à variável função, há diferenças entre as amostras, já que, na Amostra 00 (I), a cópia predomina na posição de sujeito, mas na Amostra 80 (I), esta ocorre tanto nas funções de sujeito quanto de objeto indireto. Desta forma, a cópia tem se concentrado na posição de sujeito, já que não há cópias em outras posições na Amostra 00 (I).

1 Comparação entre amostras diferentes de indivíduos gravadas com lapso temporal entre elas. No caso desta amostra, o espaço temporal é de aproximadamente vinte anos entre as gravações.

2 Estudo em que são comparadas amostras aleatórias de uma mesma comunidade de fala em diferentes recortes de tempo estratificadas de acordo com os mesmos critérios socioculturais.

3 Como no exemplo em (3). 
Outro grupo de fatores analisado foi a escolaridade, que não se mostrou um fator significativo quando observado isoladamente. Porém, ao se cruzar esta variável com as outras, nota-se que a relativa copiadora foi mais usada pelos estudantes universitários quando há a necessidade de desambiguar o referente se este é humano e se está distante da oração relativa, como no exemplo:

(3) Eu ganhei um cachorro da raça pequenez doentinho da minha professora particular que ele não sobreviveu. (MOLLICA, 2003, p.132)

Assim, Mollica (2003) conclui que a escolaridade alta é inversamente proporcional à presença das anáforas. Já a distância entre o referente e o relativo contribui para o aumento da cópia. Neste caso, a anáfora é usada como um mecanismo de retomada de referente com função de esclarecer "do que" ou "de quem" se está falando, isto é, com a função específica de tirar a ambiguidade do referente, sendo seu uso restrito aos casos em que esta desambiguação é necessária. Então, Mollica (2003) afirma que a cópia está "sofrendo uma reconfiguração no que se refere ao seu encaixamento no sistema do português brasileiro, comportando-se, na maioria das vezes, como uma estrutura com clara funcionalidade". (p.133)

Em relação à comunidade de fala, os estudos de Mollica (2003) revelaram que não há diferença significativa entre 
as amostras, separadas por um espaço de 20 anos, no que diz respeito às estratégias de à relativização. Tendo em vista as variáveis sociais, os falantes com menor idade e do sexo feminino tenderam a usar menos a cópia. Já o fator escolaridade foi relevante, mostrando um uso menos frequente da anáfora do nível médio em diante. Além do mais, foi observado que, com o aumento do nível de escolaridade, a anáfora pronominal começa a ser utilizada em contextos em que há referentes com traço humano ou animado e que se encontram longe do pronome relativo. Já em outros locais de extração preposicionados, a variante preferida é a cortadora. Ademais, os falantes de nível médio utilizam anáforas mais especificamente na posição de sujeito quando se necessita recuperar um referente distante.

No estudo de Abreu (2013), foi realizado um levantamento de todas as relativas encontradas na fala dos adultos da Amostra 00 (C) com o objetivo de identificar os padrões de distribuição das variantes de orações relativas por local de extração. Nesta amostra, 32 falantes estão estratificados em quatro faixas etárias, sendo estas: entre 9 e 14 anos, entre 15 e 25 anos, entre 26 e 49 anos e com mais de 50 anos. Estes falantes também são categorizados em quatro níveis de escolaridade, sendo estes, entre 5 e 8 anos, entre 9 e 11 anos, ou com mais de 11 anos de escolarização, correspondendo respectivamente ao 
Fundamental I, até o 5ㅇan ano, Fundamental II, até o 9o ano, e Ensino Médio. O levantamento das 1882 relativas produzidas por estes falantes revelou que o local de extração mais comum é a posição de sujeito (50\%), seguida de objeto direto (23\%), adjunto adverbial (20\%) e objeto indireto (6,3\%). Além disso, confirmou os achados de Tarallo (1993), segundo os quais as relativas de locais de extração não preposicionados tendem a ser mais produzidas em sua variante básica (ou variante padrão para Tarallo), correspondendo a $98 \%$ das relativas de sujeito e $99 \%$ das relativas de objeto direto. Já as relativas com local de extração preposicionado são produzidas com a variante cortadora, correspondendo a $74 \%$ das relativas de adjunto adverbial, e a 92\% das relativas de objeto indireto.

Portanto, de acordo com os estudos de Mollica (2003) e Abreu (2013), a comunidade de fala do Rio de Janeiro se caracteriza pelo uso mais frequente das relativas cortadoras para locais de extração preposicionados. As relativas copiadoras são usadas quando se necessita desambiguar o referente e as relativas padrão são raras em posição preposicionada. Esta distribuição corresponde ao input recebido na aquisição. Desta forma, a baixa incidência de relativas preposicionadas padrão e copiadoras no PB se refletirá na fala das crianças em idade anterior à alfabetização, juntamente com a tendência ao uso de relativas cortadoras em posições preposicionadas. 
Assim, o objetivo deste artigo é discutir e analisar a produção oral espontânea de relativas de crianças em fase aquisitiva, buscando identificar as relativas presentes na fala das crianças analisadas, além de também identificar que variantes são mais recorrentes na produção infantil. Buscase também verificar se os padrões de uso das relativas na fala dos adultos estão presentes na fala infantil.

\section{AQUISIÇÃO DE ORAÇÕES RELATIVAS SOB A ÓTICA DOS MODELOS BASEADOS NO USO}

Os trabalhos que tratam da aquisição de orações relativas na perspectiva dos Modelos Baseados no Uso sustentam o papel da experiência e do input na aquisição das orações relativas ao destacarem a importância não só da frequência de ocorrência destas estruturas, mas também de sua semelhança estrutural com outras sentenças da língua, assim como também de aspectos pragmáticos (AMBRIDGE \& LIEVEN, 2011; ARNON, 2011; DIESSEL \& TOMASELLO, 2000, 2005; DIESSEL, 2009; AMBRIDGE, KIDD, ROWLAND \& THEAKSTON, 2015; DIESSEL \& HILPERT, 2016).

O trabalho de Diessel \& Tomasello (2005), com crianças adquirindo inglês e alemão, revelou que as primeiras relativas infantis são compostas por proposições simples. Estas estruturas mais simples são formadas por um predicado 
nominal e verbo copular em uma estrutura apresentativa, conforme o exemplo a seguir, retirado de Diessel \& Tomasello (2000, p.135):

(6) Here's a tiger that's gonna scare him. ${ }^{4}$

Desta forma, Diessel \& Tomasello (2000, p.137) caracterizam as relativas infantis como proposicionalmente simples, compostas por duas orações que podem ser transformadas em apenas uma sentença como em (7):

(7) The tiger is gonna scare him. ${ }^{5}$

Em outras palavras, para Diessel \& Tomasello (2000), as primeiras relativas infantis são compostas por estruturas mais simples que geralmente fazem parte do universo concreto da criança naquele momento. Por esta razão as relativas são compostas não só por predicados nominais e verbos copulares como também por dêiticos, evidenciando o caráter concreto da produção, como pode ser observado no exemplo anterior, em que a frase, além de ser proposicionalmente simples é um comentário sobre um objeto com o qual a criança está interagindo.

Além disso, Diessel (2009) mostra que a aquisição de relativas ocorre através de um processo de expansão clausal

\footnotetext{
4 Tradução: Aqui está o tigre que vai assustar ele.

5 Tradução: O tigre vai assustar ele. Paráfrase original retirada de Diessel \& Tomasello (2000, p.137)
} 
em direção às relativas alvo produzidas por adultos. As relativas produzidas pelos adultos se caracterizam por serem mais complexas ao exprimirem duas situações, ao invés de uma como as relativas infantis. Em seu estudo com dados de produção espontânea, Diessel (2009) analisa duas crianças falantes do inglês cujas gravações estavam na base de dados CHILDES. Uma das crianças tinha 55 gravações de uma hora, registradas em intervalos regulares entre duas ou três semanas, entre as idades de 2 anos e 3 meses e 5 anos e 2 meses, que renderam 180 orações relativas. Já 210 gravações da outra criança eram de 30 minutos e foram coletadas semanalmente entre as idades de 2 anos e 4 meses e 5 anos. Estas gravações renderam 309 orações relativas. A análise dos dados considerou os seguintes aspectos: significado do verbo, função sintática do núcleo nominal, papel temático do núcleo nominal, animacidade do núcleo nominal, função sintática da função relativizada, animacidade do sujeito e objeto e tipo de sintagma nominal de sujeito e objeto.

Diessel (2009) analisou as relativas em termos da animacidade do núcleo e da função sintática relativizada e depois as dividiu em relativas de sujeito e relativas que eram de objeto direto ou adjuntos adverbiais, já que as relativas de genitivo e de objeto indireto não ocorreram nas gravações. $\mathrm{Na}$ fala das crianças, a maioria das relativas coletadas era de sujeito 
já que foram encontradas, respectivamente, 64,5\% e 57,3\% em cada criança. Além disso, o núcleo das relativas também foi categorizado em função da animacidade. Foram considerados animados animais e humanos, incluindo brinquedos, já os inanimados eram objetos e figuras abstratas. Desta forma, na fala da primeira criança, foram encontradas $78,3 \%$ das relativas com referentes inanimados e $79 \%$ na da segunda criança.

Outra questão foi a relação entre local de extração e animacidade. Diessel (2009) observou que as relativas de sujeito são comuns tanto com referentes animados quanto inanimados, já que $42,4 \%$ das relativas de sujeito ocorrem com nomes animados e as restantes com nomes inanimados. Apesar disso, as outras relativas ocorrem predominantemente com nomes inanimados, aproximadamente, em $92 \%$ dos casos. Esta relação ocorre porque geralmente os referentes animados são modificados por relativas de sujeito quando são agentes ou experimentadores ao passo que referentes inanimados são mais propensos a serem pacientes e por isso são modificados por outras relativas que não as de sujeito. Além do mais, Diessel (2009, p.266) afirma que relativas de sujeito compreendem construções diversas que variam em aspectos semânticos e pragmáticos, enquanto as outras relativas são expressas por orações transitivas envolvendo um sujeito animado, um verbo dinâmico e um objeto inanimado. 
Outra questão se refere ao tipo de sintagma nominal na posição de sujeito das relativas com outros locais de extração. Diessel (2009) afirma que cerca de 80\% das relativas possuem um sujeito pronominal e de primeira (plural ou singular) ou segunda pessoa do plural, 7,7\% são de terceira pessoa do singular, $10 \%$ são de sintagma nominal definido e o restante de sintagma nominal indefinido. De acordo com Diessel, esta distribuição reflete a distribuição das outras sentenças emitidas pelas crianças, pois o uso de pronome como sujeito é característico das orações transitivas, visto que $86,9 \%$ das relativas das duas crianças tinham sujeitos pronominais de primeira ou segunda pessoas, 7,5\% eram pronomes de terceira pessoa, 3,7\%, de sintagma nominal definido e 1,8\% de sintagma nominal indefinido. Já no caso das orações relativas de sujeito, seus sujeitos são geralmente referentes novos, então são majoritariamente $(43,30 \%)$ de sintagma nominal definidos, seguidos de sintagma nominal indefinido $(31,7 \%)$, pronome indefinido $(19,7 \%)$ e pronome demonstrativo singular (5,4\%).

Diessel (2009) observou também o tipo de verbo nas orações relativas infantis. Seu estudo revelou que as relativas de sujeito e outras relativas ocorrem com tipos de verbos diferentes, já que as relativas que não eram de sujeito apresentavam um verbo transitivo denotando atividade física 
ou cognitiva, havendo poucos verbos intransitivos nestas relativas. Estas relativas também continham mais sujeitos animados do que as relativas de sujeito. Apesar disso, para as relativas de sujeito, Diessel afirma que estas ocorrem com verbos transitivos, intransitivos ou verbos copulares, sendo maior a incidência dos dois últimos, com 43,8\%, e 37,6\% de ocorrências, respectivamente. Além disso, Diessel observa também a correlação entre os tipos de orações relativas, os verbos utilizados e a animacidade do referente. Desta forma, afirma que as relativas de sujeito, cujos verbos são intransitivos ou copulares, são mais comumente encabeçadas por nomes inanimados ${ }^{6}$. No caso dos verbos transitivos, as relativas de sujeito são mais comuns com núcleos animados. Baseandose nisso, Diessel também investigou o papel temático dos sujeitos em ambos os tipos de relativas. Foi observado que as relativas que não eram de sujeito continham sujeitos agentes ou experienciadores, ao passo que o sujeito agente nas relativas de sujeito era raro. Consequentemente, o tipo de verbo também se diferencia entre as relativas que não têm extração de sujeito e as relativas de sujeito. As primeiras são mais comuns com verbos de cognição, percepção ou comunicação ${ }^{7}$, porém as relativas de sujeito são comuns com

\footnotetext{
6 Exemplo retirado de Diessel (2009, p.269) "Look at that big truck [(dat) going some place]."

7 Exemplos traduzidos de Diessel (2009): "saber, ver e dizer"
} 
verbos estativos e que denotam posse ${ }^{8}$. Apesar disso, ambos os tipos de relativas são comuns com verbos de atividade ${ }^{9}$. Diessel (2009) investigou também a questão do tipo de referente nominal das relativas e observou que as relativas com verbos transitivos e local de extração com função de objeto direto ou de adjunto adverbial se subdividiam em quatro tipos: relativas com sujeito animado e objeto (ou advérbio) não animado, relativas com sujeito e/ou objeto animado ou advérbio, relativas com sujeito e objeto ou advérbio inanimados e, finalmente, relativas com sujeito inanimado e objeto animado ou advérbio.

Diessel (2009) conclui que as relativas infantis têm características próprias do estágio de desenvolvimento da gramática mental infantil, já que sua maioria ocorre em construções apresentativas cujos referentes são objetos presentes no momento da interação com a criança. Além do mais, estas relativas se concentram nas posições sintáticas de sujeito, objeto direto e adjunto adverbial em que as combinações com referentes inanimados são mais frequentes. Ademais, os estudos de Diessel \& Tomasello (2005) e Diessel (2009) revelaram que as relativas infantis se baseiam nas semelhanças com outras sentenças da língua.

\footnotetext{
8 Exemplos traduzidos de Diessel (2009): "ser, ter, pertencer"

9 Exemplos traduzidos de Diessel (2009): "colocar, fazer".
} 
Em outras palavras, a aquisição das relativas infantis ocorre por meio de um processo de expansão clausal em que, à medida que novas estruturas são armazenadas, passam a compor a gramática infantil, que cresce a partir de cada nova instância de uso. Desta forma, quanto maior a semelhança entre a estrutura da relativa e outras sentenças da língua, mais fácil e rápida é sua aquisição. Isto ocorre porque, na perspectiva dos Modelos Baseados no Uso, a gramática é emergente e depende da interação entre indivíduos da mesma comunidade de fala para que os padrões de fala sejam abstraídos (TOMASELLO, 2000, 2006; AMBRIDGE, KIDD, ROWLAND, THEAKSTON, 2015). Estes padrões de fala começam não só a ser armazenados como começam a fazer parte de pequenos esquemas que se ampliam com o uso. Começam a ser organizados em torno de suas semelhanças estruturais e funcionais, são abstraídos e formam um construto mental abstrato, segundo Tomasello (2000). Por essa razão, as relativas mais frequentes na fala das crianças refletem a estrutura encontrada nas sentenças mais produzidas pelos adultos, ou seja, a aquisição da estrutura relativa se apoia nas estruturas mais frequentes na língua, sendo estes padrões ampliados com mais experiências linguísticas. 


\section{METODOLOGIA E HIPÓTESES DE TRABALHO}

Para a realização desta pesquisa foram analisados dados da fala de 23 crianças da Amostra AQUIVAR/PEUL/UFRJ. Cada gravação tem em média uma hora. Nas sessões de gravação, uma pesquisadora interage com uma criança enquanto brincam com um quadro imantado com tema de praia. Para este estudo, as crianças foram organizadas em função de três faixas etárias. A Tabela 1 a seguir apresenta a distribuição etária bem como o sexo das crianças:

\begin{tabular}{|c|c|c|c|c|c|c|c|c|c|c|c|c|}
\hline Faixa etária & \multicolumn{4}{|c|}{$1,11-2,11$} & \multicolumn{4}{|c|}{$3,0-4,0$} & \multicolumn{4}{|c|}{$4,1-5,1$} \\
\hline \multirow[t]{2}{*}{ Crianças } & $\mathrm{AC}$ & CB & $\mathrm{J}$ & $\mathrm{M}$ & $\mathrm{AB}$ & $\mathrm{AG}$ & RI & ST & $\mathrm{G}$ & MA & JM & MAT \\
\hline & B & D & L & $\mathrm{R}$ & $\mathrm{S}$ & I & $\mathrm{AM}$ & & ML & $\mathrm{AN}$ & DI & MY \\
\hline Total & \multicolumn{4}{|c|}{8} & \multicolumn{4}{|c|}{7} & \multicolumn{4}{|c|}{8} \\
\hline \multirow[t]{2}{*}{ Gênero/Sexo } & \multicolumn{2}{|c|}{$\mathrm{F}$} & \multicolumn{2}{|c|}{$\mathrm{M}$} & & E & \multicolumn{2}{|c|}{$\mathrm{M}$} & \multicolumn{2}{|c|}{$F$} & \multicolumn{2}{|c|}{$\mathrm{M}$} \\
\hline & \multicolumn{2}{|c|}{7} & \multicolumn{2}{|c|}{1} & & 4 & \multicolumn{2}{|c|}{3} & \multicolumn{2}{|c|}{4} & \multicolumn{2}{|c|}{4} \\
\hline
\end{tabular}

Tabela 1: Distribuição das crianças da Amostra AQUIVAR por faixa etária e sexo. Fonte: Abreu (2013:72)

As crianças que integram a amostra usada neste trabalho são moradoras do Rio de Janeiro, com idades entre 1 ano, 11 meses e 5 anos e 1 mês, e foram agrupadas em três faixas etárias. A primeira faixa etária compreende crianças de 1 ano, 11 meses a crianças de 2 anos, 11 meses sendo compostas por 8 crianças, sendo 7 meninas e 1 menino. A segunda faixa etária é composta por 7 crianças entre 3 e 4 anos, sendo 4 meninas e 3 meninos. Já a terceira faixa etária, 
é composta por 4 meninas e 4 meninos, totalizando um total de 8 crianças entre 4 anos e 1 mês e 5 anos e 1 mês.

Desta forma, acredita-se que as faixas etárias estão bem organizadas e a distribuição de crianças no contínuo etário permite que sejam observadas as primeiras relativas infantis e os diferentes tipos distribuídos pelas diferentes faixas etárias. A hipótese que norteia este trabalho indica que as variantes de relativas mais frequentes na produção espontânea dos adultos, conforme Tarallo (1993), Mollica (2003) e Abreu (2013), e os padrões de distribuição de tipos em função do local de extração ou função sintática do relativo, revelados no estudo de Abreu (2013), estarão refletidos na produção infantil. Assim é esperado, na aquisição, que as orações de sujeito precedam as de objeto direto, e que estas precedam as de adjunto adverbial e de objeto indireto. Outro objetivo deste estudo foi verificar se as primeiras relativas infantis aparecerão em estruturas apresentativas, conforme atestou Diessel (2009) e como sugerem nossas hipóteses.

\section{RESULTADOS}

Através do levantamento realizado, foram coletadas 24 orações relativas. Estas relativas apareceram de forma crescente como também previam nossas hipóteses. Desta forma, a quantidade de relativas aumenta com o aumento da faixa etária como se pode observar na Tabela 2 a seguir: 


\begin{tabular}{|l|c|c|c|c|}
\hline \multicolumn{5}{|c}{ Distribuição de relativas na fala espontânea de crianças } \\
\hline Faixa etária & $1,11-2,11$ & $3,0-4,0$ & $4,1-5,1$ & Total \\
\hline $\mathrm{N}^{\circ}$ de crianças & 8 & 7 & 8 & 23 \\
\hline $\mathrm{N}^{\circ}$ de relativas & 2 & 5 & 17 & 24 \\
\hline
\end{tabular}

Tabela 2: Distribuição de relativas na fala espontânea de crianças na Amostra AQUIVAR/PEUL/ UFRJ. Fonte: Abreu (2013:89).

Conforme pode ser observado, foram poucas as ocorrências de orações relativas na fala das 23 crianças que compõem a amostra utilizada no estudo, além de ser uma estrutura que nem todas as crianças produziram, principalmente as crianças das duas primeiras faixas etárias. Observa-se, portanto, um aumento progressivo de ocorrências à medida que aumenta a idade das crianças. Em outras palavras, as crianças de menor faixa etária produziram menos relativas do que as crianças da segunda faixa etária que, por sua vez, produziram menos relativas do que as crianças da faixa etária III. Esta distribuição fornece evidência do papel da experiência para a aquisição, visto que as crianças mais novas têm menos experiência com a língua, ainda não construíram os esquemas mentais para abstrações destes padrões e por isso ainda não usam a relativização com frequência. Enquanto isso, as crianças da faixa etária II e III, principalmente desta última, já possuem mais experiência advinda da interação, logo já estão mais avançadas no processo de construção de sua gramática. Desta forma, a produção das relativas na faixa etária III é consideravelmente maior do que a 
quantidade de relativas das crianças mais novas. Apesar disso, das 17 relativas coletadas nesta faixa etária, 10 são de apenas uma criança. Esta distribuição também revela que há diferenças individuais entre as crianças de mesma faixa etária, mas que não podem ser controladas em uma amostra desta natureza.

Analisando-se as relativas infantis coletadas neste trabalho, observa-se também que as duas relativas encontradas na primeira faixa etária evidenciam que este mecanismo sintático é adquirido mais tardiamente, provavelmente a partir dos 3 anos. As duas relativas encontradas foram uma relativa com extração de sujeito na variante básica e uma relativa com extração de objeto indireto na variante cortadora. Esses dois dados conformam-se a nossas hipóteses no que diz respeito à variante mais frequente na fala adulta, uma vez que a variante básica de sujeito e a cortadora de objeto indireto são as variantes mais frequentes de cada tipo na comunidade de fala. Por outro lado, quanto ao local de extração, foi registrada a produção de uma oração com local de extração com função de objeto indireto, tipo de baixa frequência $(6,3 \%)$ na fala adulta, conforme mencionado anteriormente e observado no levantamento de Abreu (2013). Apesar disso, somente uma destas relativas nesta faixa etária foi construída com a estrutura apresentativa revelada por Diessel (2009), como se observa nos exemplos a seguir: 
(7) a. Relativa básica de sujeito:

Tem pica-pau, tem saci que pula assim, ó.

b. Relativa cortadora de objeto indireto:

Eu gosto que ela canta / com as crianças que ela gosta.

Com isso, observa-se que as relativas infantis ainda não são muito utilizadas na fala entre o primeiro e segundo ano de vida, portanto, sua aquisição depende de mais interações linguísticas para entrar na gramática infantil em formação. Dizendo de outra forma, até os dois anos de idade, as crianças ainda não tiveram evidências suficientes através de interações linguísticas que as possibilitassem incorporar esta construção em seus construtos mentais abstratos.

As relativas produzidas por crianças pertencentes à faixa etária II apresentam local de extração com função de objeto direto e indireto. Desta forma, das cinco relativas coletadas, três eram relativas básicas de objeto direto e duas eram relativas cortadoras de objeto indireto, conforme os exemplos a seguir:

(8) Relativa Básica de objeto direto:

Um negócio que mamãe compô.

(9) Relativa cortadora de objeto indireto:

O passarinho que eu gosto.

Já as crianças da faixa etária III, produziram 17 relativas, sendo que uma das crianças produziu a maioria delas. Esta mesma criança produziu quatro relativas padrão e uma relativa copiadora de sujeito. Além disso, produziu também 
duas relativas padrão e três relativas cortadoras de adjunto adverbial. Esta foi a criança mais produtiva no uso da relativização. As outras relativas coletadas na mesma faixa etária foram quatro relativas padrão de sujeito, produzida por MAT, uma relativa cortadora de adjunto adverbial produzida por ML, uma relativa básica de sujeito e uma relativa cortadora de adjunto adverbial produzida por MY.

Além disso, as relativas encontradas foram analisadas em função de sua estrutura. De acordo com as hipóteses de trabalho, as relativas infantis serão em sua maioria encontradas em estrutura apresentativa, de acordo com Diessel (2009). Esta hipótese foi confirmada já que a maioria das relativas, 18 ocorrências, eram orações apresentativas, representando $75 \%$ das relativas coletadas, conforme os exemplos a seguir:

(10) Relativa cortadora de adjunto adverbial de Tempo: Aquele dia que eu tirei foto?

(11) Relativa de Sujeito:

Tem algumas que são gordas e eu não gosto.

(12) Relativa de Objeto direto:

Esse é o livro que a dinda ganhou.

Estas relativas seguem o tipo apresentativo, identificado por Diessel \& Tomasello (2000, 2005), em que as relativas representam apenas um estado de coisas, e são iniciadas por dêiticos ou pronomes demonstrativos, como no primeiro e 
terceiro exemplos. Além disso, neste estudo foi encontrada oração relativa encaixada em uma oração introduzida pelo verbo "ter" com sentido de existir, como no segundo exemplo, similar à construção "There's", como relatado por Diessel \& Tomasello (2000). Também foram encontradas duas relativas padrão com local de extração preposicionado, porém todas as sentenças produzidas eram encabeçadas pelo relativo onde, como na relativa padrão de adjunto adverbial a seguir:

(13) Eu já empinei uma pipa lá onde fica os cachorros.

As outras 6 relativas eram com estruturas complexas assim como no exemplo 7b acima, em que há duas orações. Esses casos correspondem a uma minoria do total de 23 relativas infantis encontradas, evidenciando o processo de aquisição das relativas pelo qual as crianças estavam passando até produzirem relativas alvo.

Ademais, houve 8 relativas cortadoras nas posições de objeto indireto, como no exemplo 7b, e na posição de adjunto adverbial como no exemplo a seguir:

(14) Tem uma mesa perto da minha janela que eu estudo sozinha.

Estas relativas cortadoras se concentraram mais nas crianças da terceira faixa etária. Já as relativas cortadoras de objeto indireto já aparecem na primeira e segunda faixas 
etárias. O aparecimento de relativa com local de extração com função de objeto indireto não era esperado na fase inicial, nem mesmo a variante cortadora, já que não é uma variante frequente no input. No entanto, a estrutura da variante cortadora corresponde a um tipo estrutural frequente na língua, o que pode explicar sua ocorrência. Em outras palavras, as relativas cortadoras de objeto indireto não são as mais frequentes no input, porém apresentam a ordem sujeito-verbo-objeto (SVO), sendo o objeto nulo, neste caso, que é um tipo estrutural muito produtivo no PB para as sentenças simples. Então, a similaridade estrutural das relativas cortadoras de objeto indireto com outras sentenças da língua faz com que este tipo de relativa já esteja presente nos primeiros anos de fala das crianças. Isto demonstra uma especificidade do PB em relação à aquisição de relativas, já que nos dados de Diessel (2009) não são encontradas relativas de objeto indireto em crianças adquirindo o inglês. Logo, a variante cortadora das relativas de objeto indireto possibilita o surgimento das relativas de objeto indireto na produção espontânea de crianças nos primeiros anos de vida.

Outra análise feita por Diessel (2009) foi com relação aos tipos de verbos encontrados nas relativas com relação a seus aspectos sintáticos e semânticos, juntamente com 
os tipos de referentes caracterizados pelas relativas. Nas análises de Diessel (2009), o aspecto sintático compreendia a transitividade verbal e o aspecto semântico compreendia o significado do verbo, categorizando-os em três tipos, como já mencionado anteriormente. Neste levantamento, foram encontrados dois verbos transitivos indiretos, gostar e brincar, sendo o primeiro um verbo de sentimento e o segundo, um verbo que exprime atividade. Ademais, foram encontrados seis verbos intransitivos: pular e estudar, que exprimem atividades; ser, estar e ficar, que exprimem permanência ou estado; e ir, que é um verbo de movimento. Foram encontrados também sete verbos transitivos diretos, sendo eles comprar, ganhar, pegar, tirar, pendurar-se e fazer, que exprimem ações físicas, e o verbo chamar. Desta forma, observa-se que a maioria dos verbos codifica ações físicas, movimento e sentimento, conforme Diessel (2009) havia descrito para as relativas produzidas por crianças inglesas e alemãs.

Além disso, ao analisar os referentes encontrados nas relativas infantis, também encontramos semelhanças com o que foi revelado no estudo de Diessel (2009), já que são encontrados muitos referentes animados, humanos ou não, sendo a maioria dos referentes relacionados ao universo concreto da criança. Desta forma, os referentes foram 
divididos em três categorias, denominadas na presente pesquisa como: os circunstanciais, os animados e os inanimados. Denominaram-se circunstanciais os referentes dia, praia, lá, campo, fim de semana, teatro do Peter Pan e uma vez, já que todos exprimem uma referência temporal ou espacial no contexto em que foram realizados, sendo assim, estão, na sua maioria, com função de adjunto adverbial de tempo ou lugar. Outros referentes podem ser caracterizados como animados, como crianças, saci, passarinho, menino, garoto, amiga, fadinhas e artista, visto que denominam seres reais ou imaginários capazes de exercer ações. Estes referentes se concentraram nas relativas de sujeito, sendo somente dois referentes animados em posições de objeto indireto. A categoria dos inanimados é composta pelos referentes que não têm uma referência definida, mas designam objetos, e os objetos propriamente ditos, como: negócio, negocinho e coisa (sem referência definida), livro e mesa. Estes referentes estão concentrados na posição de objeto direto e somente um na de objeto indireto.

Com respeito ao papel temático, a maioria dos referentes das relativas de sujeito eram agentes, a maioria dos referentes circunstanciais era de locativos e os inanimados eram, em sua maioria, experienciadores ou pacientes. Desta forma, conclui-se que as relativas encontradas na produção 
espontânea de crianças cariocas entre 1 ano e 11 meses e 5 anos e 1 mês se assemelham aos dados obtidos por Diessel (2009) tanto em aspectos sintáticos quanto semânticos.

\section{CONCLUSÃO}

Com base nos dados coletados da produção espontânea de crianças cariocas, foi possível traçar algumas tendências na aquisição de relativas. Embora poucas relativas tenham sido encontradas na fala das 23 crianças, a sua estrutura de relativização tem muito em comum com o descrito por Diessel \& Tomasello (2000, 2005) e Diessel (2009), para crianças inglesas e alemãs, em termos de suas especificidades em relação à fala dos adultos. Isto confirma a hipótese sobre a gradualidade na aquisição de relativas, já que mostra mais uma evidência do papel do input e da experiência linguística na emergência da gramática. Desta forma, observou-se que tanto as crianças inglesas e alemãs como as brasileiras começam o uso da relativização com estruturas mais simples, apresentativas e frequentes, até amadurecerem linguisticamente para produzir outras relativas presentes na fala dos adultos. Este processo de maturação ocorre gradualmente a partir do desenvolvimento cognitivo da criança, tendo por base a interação com outros falantes de sua comunidade de fala. Assim, as relativas produzidas na fala 
infantil se concentram em estruturas mais simples e caminham para relativas complexas que de fato encaixam duas situações. Ademais, tendências de uso observadas na fala de adultos de acordo com local de extração e variante também são observadas na fala infantil, visto que constituem a base para a aquisição da estrutura relativa, já que os tipos de relativas mais encontrados na fala dos adultos se refletem na fala infantil.

Também foi observado que a similaridade estrutural das variantes de relativa com outras estruturas da língua influencia a aquisição, já que, embora as variantes cortadoras de objeto indireto tenham baixa frequência no input, são encontradas na fala infantil. Neste caso, sua semelhança com sentenças simples do PB, no que diz respeito à ordem de seus constituintes - ordem SVO, pode explicar sua produção por crianças da primeira faixa etária. Desta forma, este trabalho também amplia as evidências sobre a importância da experiência, da frequência de uso, e da semelhança estrutural para a aquisição da linguagem e emergência da gramática conforme afirmam Tomasello (2000 e 2006), Diessel e Tomasello (2005), Diessel (2009) e Diessel \& Hilpert (2016) e Ambridge, Kidd, Rowland, Theakston (2015).

Ainda, com relação às variantes manifestas na produção espontânea das crianças da amostra, observa-se a ausência da 
variante padrão das funções preposicionadas nos dados, de objeto indireto e adjunto adverbial, contendo a preposição e o pronome relativo. O comportamento observado pode ser tomado como mais uma evidência do estágio da mudança que envolve as funções preposicionadas, no sentido de que as variantes padrão não estão mais disponíveis ou não são mais transmitidas de uma geração para outra da comunidade de fala.

\section{REFERÊNCIAS}

ABREU, Ana Cristina Baptista (2013). Aquisição de orações relativas no Português Brasileiro. (Dissertação de Mestrado), UFRJ.

AMBRIDGE, Ben; LIEVEN, Elena (2011). Child language acquisition: Contrasting theoretical approaches. Cambridge University Press. ; KIDD, Evan; ROWLAND, Caroline; THEAKSTON, Anna (2015). "The ubiquity of frequency effects in first language acquisition". Journal of Child Language, 42(2), 239-273.

ARNON, Inbal (2011). "Relative clause acquisition in Hebrew and the learning of constructions". In: Kidd, Evan (Ed.) The Acquisition of Relative Clauses: processing, typology and function. Amsterdam: John Benjamins. p.107-139.

DIESSEL, Hoger (2009). "On the role of frequency and similarity in the acquisition of subject and non-subject relative clauses" In: GIVÓN, Talmy and SHIBATANI, Masayoshi (Eds.), Syntactic Complexity, 251-276. Amsterdam: John Benjamins, p.251-276.

; Hoger; HILPERT, Martin (2016). "Frequency effects in grammar". In: ARONOFF, Mark (Ed.), Oxford Research Encyclopedia of Linguistics. New York: Oxford University Press, p.1-30.

; TOMASELLO, Michael (2005). "A new look at the acquisition of relative clauses". Cognitive Linguistics, 81(4), 882-906. 
(2000). "The development of relative clauses in spontaneous child speech". Cognitive Linguistics 11, 131-151.

LABOV, William (2007). "Transmission and diffusion". In Language 81(2), 344-387.

(2010). Principles of Linguistic Change: Cognitive and Cultural factors. Vol.3. Oxford: Wiley-Blackwell.

LESSA DE OLIVEIRA, Adriana S. C. (2008). As sentenças relativas em português brasileiro: aspectos sintáticos e fatos de aquisição. (Tese Doutorado), Unicamp.

MOLLICA, Maria Cecília (2003). "Relativas em tempo real no português contemporâneo". In: PAIVA, Maria Conceição; DUARTE, Maria Eugênia Lamoglia (Orgs.). Mudança Linguística em Tempo Real. Rio de Janeiro: Contracapa, p.129-138.

PERRONI, Maria Cecilia (2001). "As relativas que são fáceis na aquisição do português brasileiro". DELTA. 17(1), 59-79.

TARALLO, Fernando (1986). "Functional and Structural Properties in a Variable Syntax". In: SANKOFF, David (Ed.) Diversity and Diachrony, vol.53. Amsterdam: John Benjamins Publishing, p.249-260.

(1993). "Diagnosticando uma Gramática Brasileira: O português d'aquém e d'além mar ao final do século XIX". In: ROBERTS, Ian; KATO, Mary. (Orgs.) Português Brasileiro: uma viagem diacrônica. Homenagem a Fernando Tarallo. Campinas: Unicamp, p.69-100.

TOMASELLO, Michael (2000). "Do young children have adult syntactic competence?" Cognition, 74, 209-253.

(2006). "Acquiring linguistic constructions". In: KUHN, D.; SIEGLER,

R. (Eds.), Handbook of Child Psychology. New York: Wiley.

WEINREICH, Uriel; LABOV, William; HERZOG, Marvin I. (1968). "Empirical Foundations for a Theory of Language Change". In: LEHMANN, W. P.; MALKYEL, M. (Orgs.). Directions for Historical Linguistics. Austin: University of Texas Press. p.97- 195. 
Ana Cristina Baptista de Abreu é Doutoranda pelo Programa de PósGraduação em Linguística da UFRJ e bolsista CAPES e Mestre em Linguística pela UFRJ. Participa do grupo de pesquisa Programa de Estudos sobre o Uso da Língua (PEUL/UFRJ). Seus trabalhos são referentes à aquisição de sintaxe variável. E-mail: anacristina.abreu@hotmail.com.

Christina Abreu Gomes é Doutora em Linguística pela UFRJ e Mestre em Linguística pela UFMG. Professora Titular da UFRJ e Bolsista de PQ do CNPq. Desenvolve e orienta Mestrado e Doutorado na área da variação e mudança linguística, com ênfase na aquisição da variação e na emergência de padrões sonoros variáveis do Português Brasileiro. Tem publicação de artigos, livros e capítulo de livros e integra os Grupos de Pesquisa Programa de Estudos sobre Uso da Língua (PEUL/UFRJ) e Fonologia Cognitiva: investigação de padrões sonoros emergentes (UFMG). E-mail: christina-gomes@uol.com.br. 